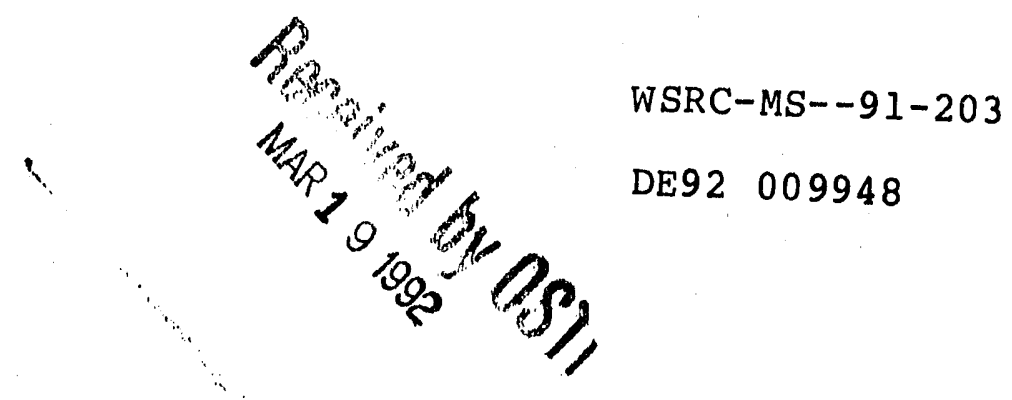

\title{
DEVELOPING A COMPREHENSIVE TRAINING RECORDS AND INFORMATION SYSTEM USING ORACLE (U)
}

by

C. Page and M. Winn

Westinghouse Savannah River Company

Savannah River Site

Aiken, South Carolina 29808

A paper proposed for presentation and publication at the

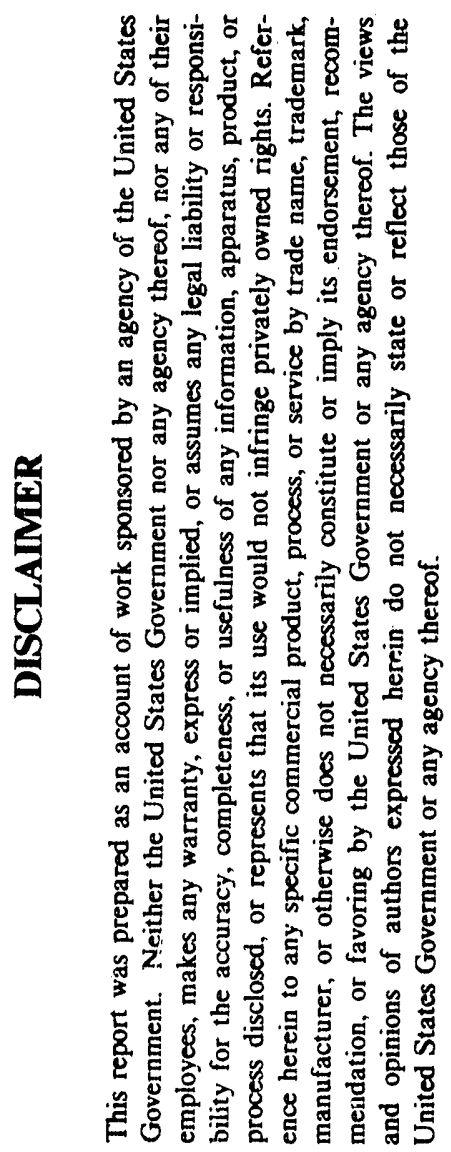

Westinghouse Computer Symposium

Monroeville, Pennsylvania

October $21-22,1991$

This paper was prepared in connection with work done under Contract No. DE-AC09-89SR18035 with the U.S. Department of Energy. By acceptance of this paper, the publisher and/or recipient acknowledges the U.S. Government's right to retain a nonexclusive, royalty-free license in and to any copyright covering this paper, along with the right to reproduce and to authorize others to reproduce all or part of the copyrighted paper. 


\title{
Developing a Comprehensive Training Records And Information System Using ORACLE
}

\author{
By: \\ Charles Page \\ Marilyn Winn \\ Westinghouse Savannah River Company \\ Savannah River Site \\ 707-49B \\ Aiken, SC 29808 \\ (803) 644-4580 \\ (803) $952-7849$
}

Westinghouse Computer Symposium

Radisson Hotel

Monroeville, Pennsylvania

October 1991 


\title{
Developing a Comprehensive Training Records And Information System Using ORACLE
}

\author{
By: \\ Charles Page \\ Marilyn Winn \\ Westinghouse Savannah River Company \\ Savannah River Site \\ 707-49B \\ Aiken, SC 29808 \\ (803) 644-4580 \\ (803) 952-7849
}

\begin{abstract}
As a result of Department of Energy orders and the need to improve the quality and management of employee training information, Westinghouse Savannah River Company (WSRC), Training Integration is charged with developing and implementing a sitewide automated and fully integrated Training Records And Information Network (TRAIN).

TRAIN is a sitewide training support system developed in ORACLE for use by line management and training personnel. The TRAIN system follows the Performance-Based Training (PBT) methodology and is designed to accomplish the following:

- support accreditation efforts

- standardize training records and processes

- provide management with current training information, and

- meet changing requirements in a timely, cost-effective manner

The system will utilize the site network to electronically access comprehensive training histories for site employees; course development information; centrally managed computer-based training; automated exam generation; course, instructor, and facility evaluation information; and automated course scheduling.
\end{abstract}

The information in this article was developed during the course of work under Contract No. DEAC09-89SR18035 with the U.S. Department of Energy. 


\section{Introduction}

As a result of Department of Energy orders, audit findings, and the need to improve the quality and management of employee training information, a sitewide automated training support system named TRAIN (Training Records And Information Network) is being developed and implemented at the Savannah River Site (SRS). Currently, numerous departmental databases exist on various hardware and software combinations prohibiting the ability to obtain comprehensive employee training histories and related information.

With the implementation of TRAIN, SRS will be in compliance with the following DOE Orders which reference the need to maintain employee training records and other related information:

$\begin{array}{ll}5480.18 & \text { "Accreditation of Performance-Based Training for Category A } \\ \text { Reactors and Nuclear Facilities" } & \\ 5480.20 & \text { "Personnel Selection, Qualification and Training Requirement" } \\ 5480.1 B & \text { "Environment, Safety, and Health Programs for Department of Energy } \\ 5480.5 & \text { Operations" }\end{array}$

The TRAIN application is being developed in modules and implementation will be phased module by module and division by division. Employee Training History (Records) is the first module to be developed and implemented. The TRAIN software is developed in ORACLE and runs on a VAX/VMS platform. It can be accessed from MacIntosh or IBM personal computers. The software is being developed by Information Systems Engineering (WSRC), Training Integration (WSRC) and ORACLE personnel.

In order to ensure data integrity and reduce redundancy of data, interfaces between TRAIN and other sitewide databases such as TESSERACT (personnel/payroll system), Organizational Breakdown Structure (WSRC organization chart) and IMPACTS (commitment management system) are being established.

\section{TRAIN Scope and Purpose}

The purpose of TRAIN is to provide WSRC with a single, easily accessible repository for training information. The system is designed to accomplish the following:

- support accreditation efforts

- standardize training records and processes

- provide management with current training information

- meet changing requirements in a timely, cost-effective manner

TRAIN follows the Performance-Based Training (PBT) methodology. The six business functions defined in the system requirements are analyze job requirements; design, develop, implement and evaluate training; manage/monitor training. TRAIN will be developed in the following modules: 
Employee Training History provides an employee's complete training history in an easily auditable format. The history includes personnel data; qualification and certification information; job experience; and training courses completed including exam grades. Personnel qualified to perform specific jobs can be identified.

Job and Task Analysis (ITA) addresses the analysis phase of the PBT. Each job has a title, location, duties, tasks, elements and skills/knowledge. A Task to Training Matrix is developed.

This data will ensure that training programs are oriented specifically to the tasks associated with a specific job position.

Training Material Design and Development supports the design and development, phases of the PBT methodology. It provides instructional designers with a tool to construct training programs with objectives that are linked to the tasks defined for specific jobs iri the Job and Task Analysis module. The development of programs into courses, modules and units is documented.

Training Development Request (TDR) provides the documented evidence associated with each item being reviewed and analyzed for its impact on the training process. Commitments which impact training are tracked through an action plan which details the steps required to close out commitments. The status of commitments can be reported via predefined forms or ad hoc queries.

Scheduling provides the mechanism for scheduling classes and assigning students to these classes. Course and class waiting lists will be maintained. On-line access to the WSRC Training Catalog will be provided. Notification of pending qualification expiration dates will be sent to employees and their managers. Employee records will be updated to reflect class attendance and completion of training requirements.

Evaluation provides the critical feedback to ensure that training is current and is adequately satisfying job requirements. Data is collected and stored for programs, courses, modules, units, training facilities, and instructor and student performance.

Exam Generation software will be selected and integrated into TRAIN. The software will provide the ability to write exam questions, maintain exambank questions with graphics, generate exams which meet security requirements, and maintain exam design history information. The exam results will be passed from the PC to the VAX.

Manage, Monitor Training functions include: maintaining class attendance records; developing and maintaining an individual training plan for each employee; producing a report of an employee's training record for verification; generating information for the annual site training program plan for submission to DOE; support for career path planning by identifying personnel with specific skills, experience, and education for WSRC job openings.

Centrally Managed Computer Based Training will be developed for delivery in a multivendor environment and accessible via the site network. 


\section{Development and Implementation}

The system requirements for TRAIN were established utilizing the joint application design process by a ten member team (TRAIN JAD Team) representing division training organizations across the site. The requirements document was reviewed and approved by the team and division training managers in April 1990. Six business functions and 115 entities were identified.

A software search was conducted which evaluated over 18 applications from other DOE sites, commercial nuclear plants and vendors. The application which best met the system requirements was the Training Management Information System developed by the Reactor Division of WSRC. This application was further functionally and technically evaluated. The feasibility study was completed in July 1990.

Several members of the TRAIN JAD Team became a part of the User Design Team which assisted with field definition and form layout for the Employee Training History module (first TRAIN module). A prototype was developed and reviewed. The design document was approved February 1991. A comprehensive sizing of the system was completed by Information Resource Management (WSRC) personnel and an ORACLE consultant. The long-range hardware strategy recommends the establishment of a cluster environment for the development, production and training machines. Currently the hardware consists of a VAX 6310 (development) and a VAX 6520 (production/training). Figure I pictorially presents the TRAIN Overall configuration.

Prior to implementation of the Employee Training History module within a division, personnel from Training Integration and Westinghouse Productiivity and Quality Center will perform an initial assessment of the individual training files (paper-based system) and assist all WSRC divisions with the implementation of the standard manual training record system. Existing training databases will be reviewed and data converted to the TRAIN format. Before user accounts are established, the individual must successfully complete training on the TRAIN applicaion.

Training and user documentation will be developed and provided for each module of TRAIN. The level of required training is determined by a user's job function and a matrix of required courses has been established. Courses for the Employee Training History module are as follows:

- TRAIN Overview

- Data Definition

- Data Input and Maintenance

- Monitoring and Reporting

The Employee Training History module was implemented ir . September 1991. Analysis and design of the second module, Scheduling began in September 1991. Full implementation (to include all modules) of the TRAIN system in all WSRC divisions is estimated to take a total of five years. 


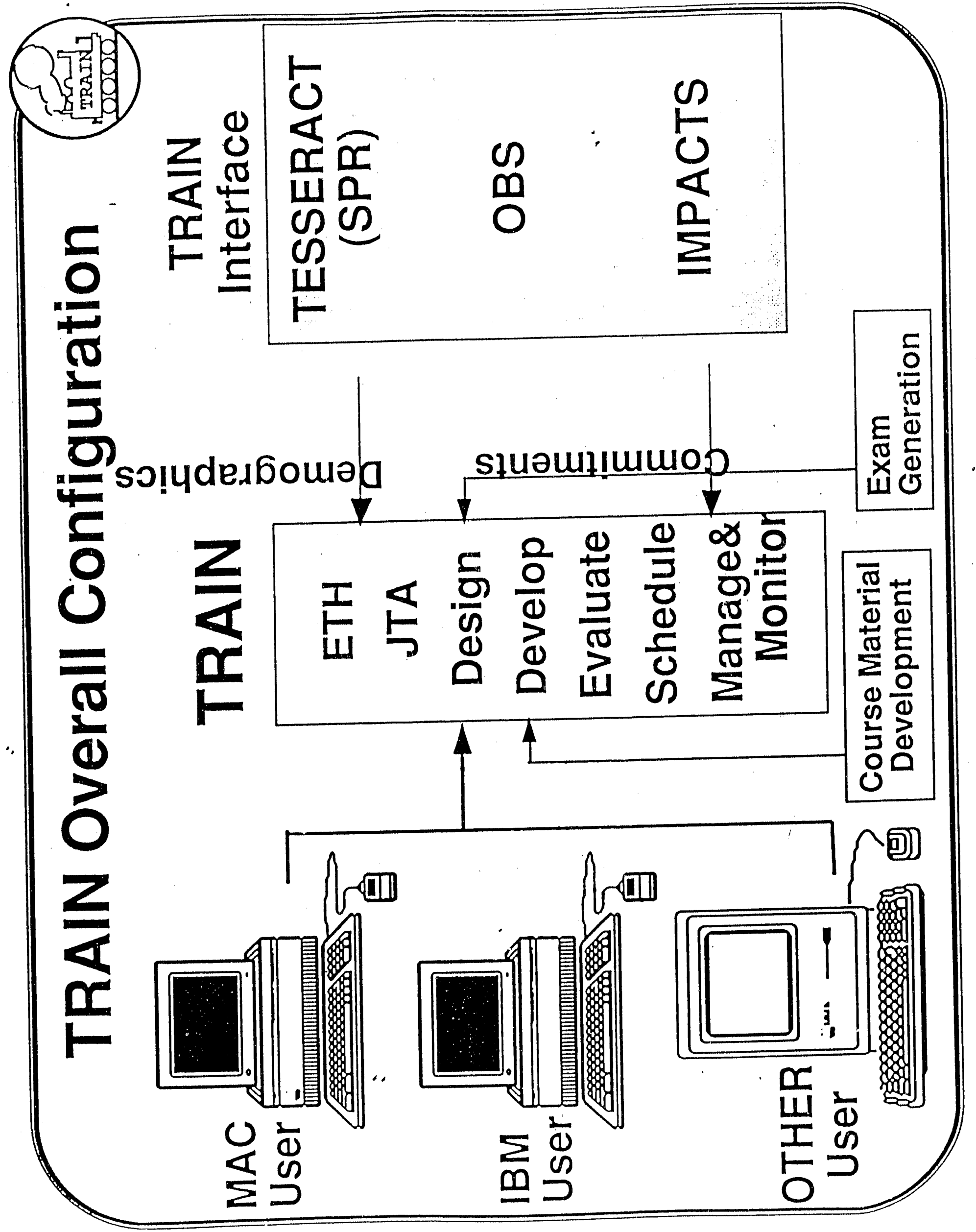




\section{TRAIN FUNCTIONS AND CAPABILITIES}

TRAIN has been developed with functions and capabilities which are intended to provide the user with an easy to use and secure application. TRAIN screens have been developed which provide features to support the TRAIN Database Administrator's role in a user-friendly manner.

TRAIN has been developed, as stated previously, using ORACLE on DEC VAX/VMS platform. TRAIN is using the following ORACLE products:

* ORACLE RDBMS version 6.2

* SQL*FORMS version 3.0

* Reportwriter version 1.1

* SQL*MENU version 5.0

The following sections summarize a subset of the features, capabilities and functions which have been utilized or developed within TRAIN. The sections will specify :

* Menu options

* System security

* "User Friendly" features

* Reporting Capabilities

* DBA Options

\section{Menu}

TRAIN uses the "Pull-down" menu style in SQL*MENU. The "Pull-down" style was selected because of its similarity to many of the PC-based software packages. Users are familiar and prefer this style over the it traditional "Full-page" option. The "Pull-down " style allows the TRAIN user to navigate through the system using two methods. By using the "arrow" or "tab" key to position the cursor on the menu option or by typing the upper-case character of a menu option to immediately access a form.

The "Pull-down" style will also be readily adaptable to a "bit mapped" environment which will provided in a future release of $S Q L^{*} M E N U$. When this environment is 
available, the user will have full usage of the "mouse" to interact with the TRAIN menu.

\section{System Security}

TRAIN will have three levels of security. The first will be at the traditional operating system level. This will require users to have a valid VAX account established prior to entry into TRAIN.

The second level of security is provided at the TRAIN menu. Users are assigned a job function (or category code) on the user table. The job function code is used to limit the menu options which are accessible to the user. For example, a job function of DBA which is category code " 1 ", allows the user to view and interact with all of the menu options. Consequently the user may access all of the screens which are below the menu options. However a job function of Training Coordinator will limit the user to see only two menu options. Correspondingly the user may only interact with the screens below those menu options.

The third level, "Row Level Security", limits the records a user may view or update. This level of security is based upon an organization code which is assigned to the user's account in the user table. This level of security will prevent one organization from viewing or updating another organization's data.

\section{"User Friendly" Features}

TRAIN has several features which facilitate ease of use. A few of these features are discussed below.

\section{Field Validation}

Required fields are validated upon entry into the TRADN application. Fields that are validated against validation tables provide the user with a "List of Values" (LOV) option. The LOV allows the user to view and select via a "pop-up" window , the valid entries for a field. This feature reduces the potential user frustration which may accompany entry of invalid data.

\section{Dialogue Boxes}

Dialogue Boxes are "pop-up" windows which either emphasize to the user the consequences or results of their actions this augments the applications "Message Line" or based upon user input presents the user with an option to start a process. Another usage of the Dialogue Box is presented within the Quick Navigation discussion which follows. 


\section{Quick Navigation}

TRAIN uses two methods to permit the user to quickly move from screen to screen. The first method, the sub-menu, permits the user to invoke the TRAIN sub-menu options from within a screen. The user upon pressing the "sub-menu" key may select any of the screens that are present on the sub-menu. The user may then interact with the screen as if the screen had been selected via normal methods. Upon exiting the screen the user is returned to the original calling form.

The second method of quick navigation is facilitated via a Dialogue Box. Based upon user input (predominantly concerning invalid input) the user is presented with an option, via a dialogue box, to navigate to another screen. If the user chooses to move to another screen the system will call the requested form. The user may then proceed with normal interactions in the screen. Upon exiting the called screen, the user is returned to the original one.

\section{Soft Keys}

TRAIN will be accessed predominantly via two platforms. The IBM/PC and the Apple MacIntosh. Both platforms will use Pacer Link as the communication emulator. Pacer Link as implemented on the MacIntosh allows the user to point and click on a "softkey" instead of the keyboard to invoke a TRAIN command. The user is presented with a template of the TRAIN keys at the top of the screen. The user has only to position the mouse on the "soft-key" and "click" to invoke the command.

\section{Reporting Capabilities}

TRAIN provides two screens which aid the user in retrieving information. The first of these screens, Report Parameter, permits the user to input information which will restrict the report.'s content. For example, a user may via a parameter screen request that a report be generated for an entire organization or for an individual.

The second screen, Report Destination Options, provides the user with the ability to select a output destination. Using this screen the user may direct output to a local printer attached to a PC, direct the output to the screen, send output to a system printer or place the output into a VMS file. The succeeding figures, display both the Report Parameter and Report Destination Options screens.

\section{DBA Options}

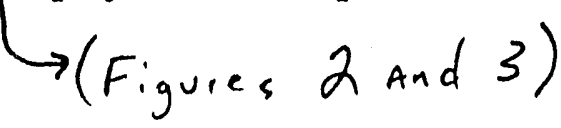

TRAIN's DBA Options were developed to provide the DBA with tools to aid with the application's maintenance. A few of these tools are discussed below. 


\section{DBA Scripts}

Scripts have been developed which reduce the effort involved in dropping (deleting)and then recreating an ORACLE table. Normally, after a table has been dropped in order to recreate the table the DBA must reenter the column or field names, sizes, domain, etc. By using the scripts the DBA does not have to reenter the table characteristics.

\section{Verify Data Integrity}

Reports have also been developed which insure the integrity of the database. The reports verify that data dependencies are maintained. It should be noted however, that the TRAIN screens also ensure the data's integrity. The reports are an added level of security.

\section{Maintain User Accounts}

The User Maintenance screen allows the DBA to establish TRAIN user accounts. Using this screen the DBA may enter the organization and category codes which are required for the application's security. The DBA also has the ability to assign a user to a specific database. That is , the DBA may point a user to either the Production, Test or Archived database via this screen. When the data entered is committed (saved), the application will start scripts which grant access privileges to users. Normally, this is a tedious process, however, the user maintenance screen simplifies the process significantly.

\section{Scheduler}

Scheduler is an ORACLE application developed independent of TRAIN. Scheduler allows the DBA (or user) to schedule batch processes to run at specific times. Reports or jobs may be schedule $d$ to run on a reoccurring basis. They may be scheduled to process only once, hourly, daily, weekly, etc. 


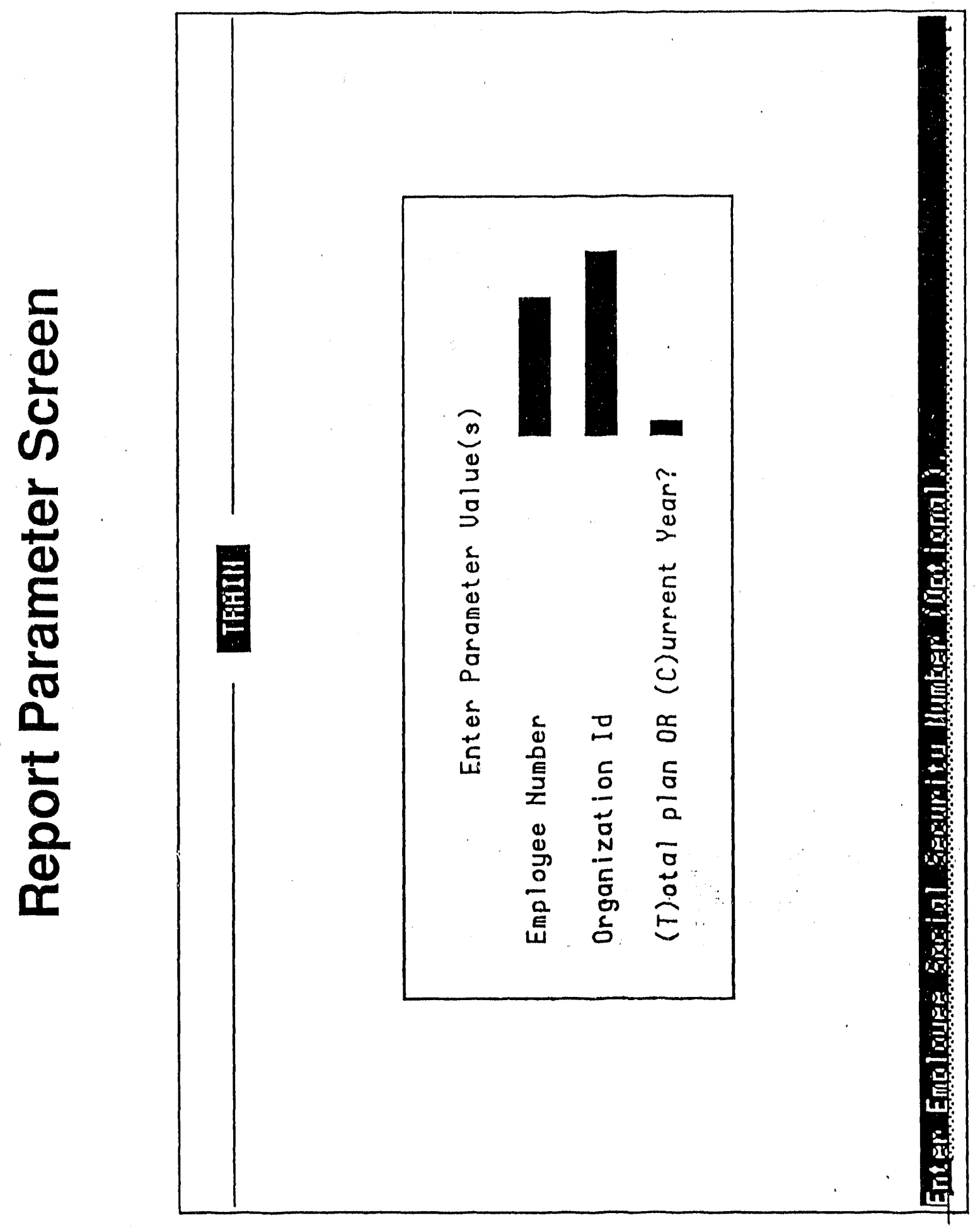




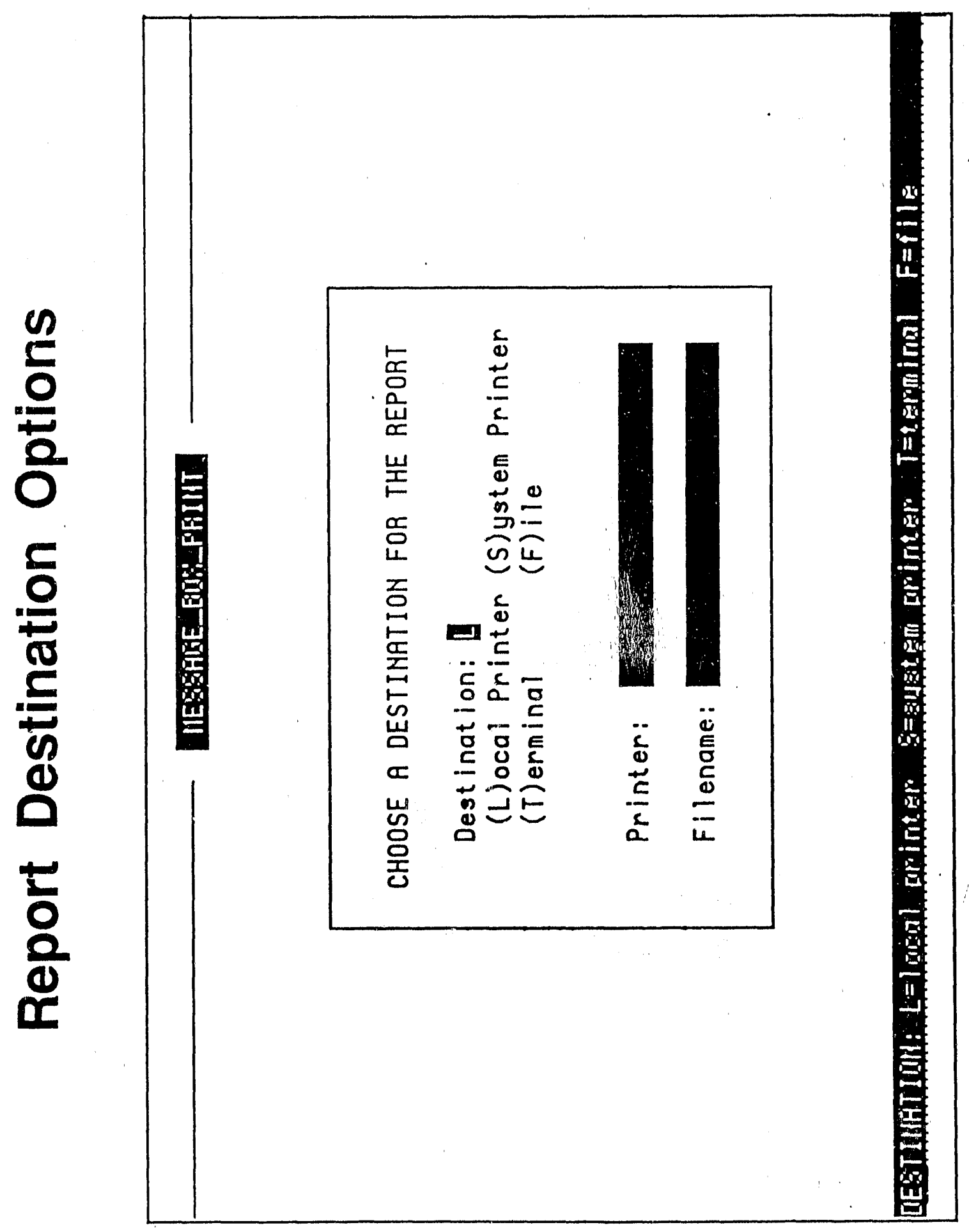




\section{Summary}

As the acknowledgement of training and its development process, as integral parts of the company's success, continues to grow, the need for automated systems will continue to increase.

The implementation of the Employee Training History Module is the first step in satisfying a portion of the increased automation requirements. A significant effort still remains in developing future modules of the application. However, even more effort is required to introduce and train WSRC to the new Performance Based Training frocess. 

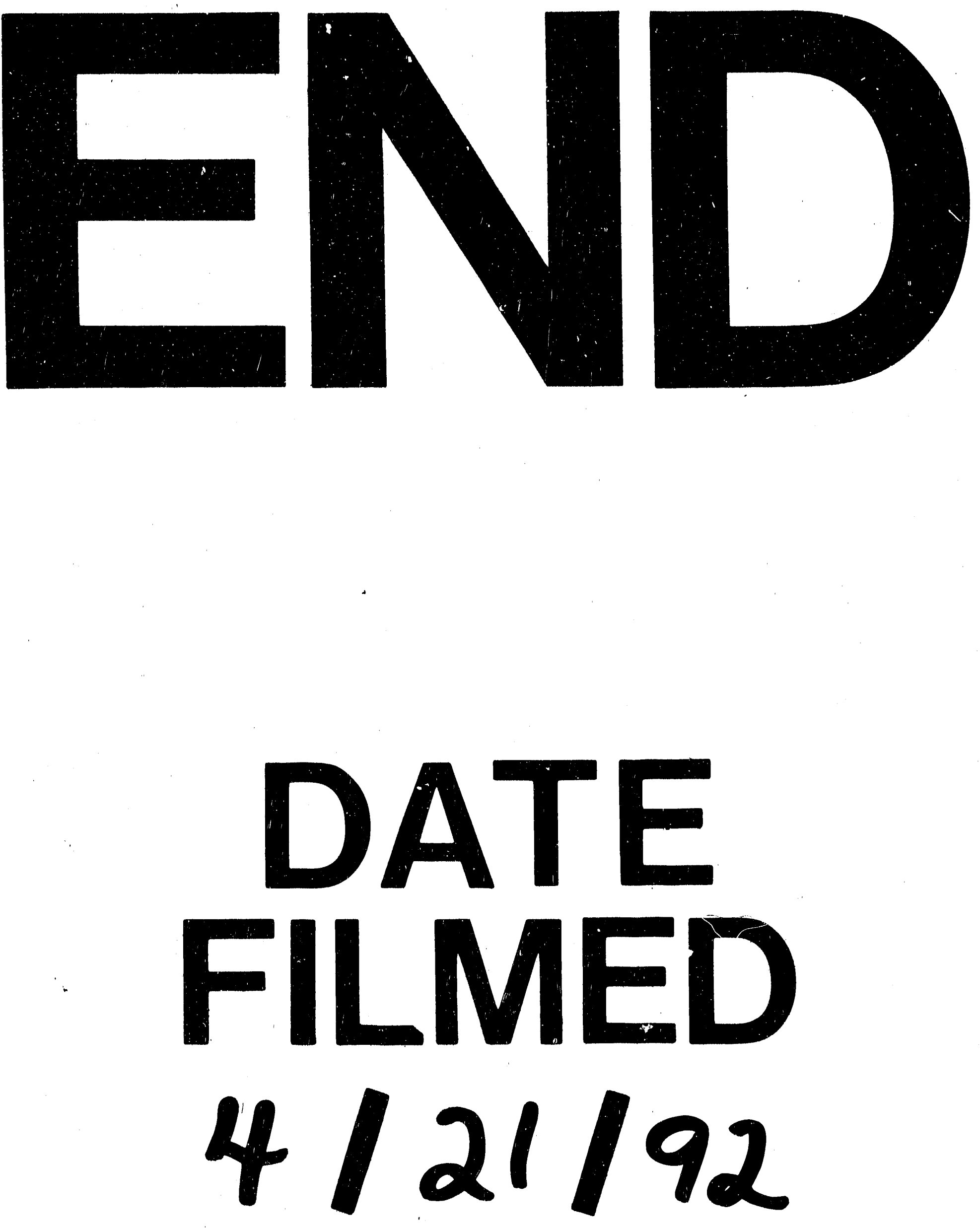

1 
